\title{
Non-face-to-face physical activity interventions in older adults: a systematic review
}

\author{
Andre Matthias Müller ${ }^{*}$ and Selina Khoo
}

\begin{abstract}
Physical activity is effective in preventing chronic diseases, increasing quality of life and promoting general health in older adults, but most older adults are not sufficiently active to gain those benefits. A novel and economically viable way to promote physical activity in older adults is through non-face-to-face interventions. These are conducted with reduced or no in-person interaction between intervention provider and program participants. The aim of this review was to summarize the scientific literature on non-face-to-face physical activity interventions targeting healthy, community dwelling older adults ( $\geq 50$ years). A systematic search in six databases was conducted by combining multiple key words of the three main search categories "physical activity", "media" and "older adults". The search was restricted to English language articles published between $1^{\text {st }}$ January 2000 and $31^{\text {st }}$ May 2013. Reference lists of relevant articles were screened for additional publications. Seventeen articles describing sixteen non-face-to-face physical activity interventions were included in the review. All studies were conducted in developed countries, and eleven were randomized controlled trials. Sample size ranged from 31 to 2503 participants, and 13 studies included $60 \%$ or more women. Interventions were most frequently delivered via print materials and phone $(n=11)$, compared to internet $(n=3)$ and other media $(n=2)$. Every intervention was theoretically framed with the Social Cognitive Theory $(n=10)$ and the Transtheoretical Model of Behavior Change $(n=6)$ applied mostly. Individual tailoring was reported in 15 studies. Physical activity levels were self-assessed in all studies. Fourteen studies reported significant increase in physical activity. Eight out of nine studies conducted post-intervention follow-up analysis found that physical activity was maintained over a longer time. In the six studies where intervention dose was assessed the results varied considerably. One study reported that $98 \%$ of the sample read the respective intervention newsletters, whereas another study found that only $4 \%$ of its participants visited the intervention website more than once. From this review, non-face-to-face physical activity interventions effectively promote physical activity in older adults. Future research should target diverse older adult populations in multiple regions while also exploring the potential of emerging technologies.
\end{abstract}

Keywords: Media, Non-face-to-face interventions, Older adults, Physical activity, Systematic review

\section{Introduction}

The United Nations (UN) reported that in 2012 about 810 million people were 60 years or older. It was further projected that by 2050 the global community will consist of more than two billion older adults [1]. Thus, the World Health Organization (WHO) described the phenomenon of population aging as one of three major factors influencing global health [2], because older age is closely associated with chronic multi-morbidity [3] and high health care costs $[3,4]$.

\footnotetext{
* Correspondence: andrematthiasmueller@gmail.com

Sports Centre, University of Malaya, 50603 Kuala Lumpur, Malaysia
}

An effective non-pharmaceutical way to prevent chronic diseases, increase quality of life and promote general health in older adults is through physical activity (PA) [5-7]. Recent evidence suggests that PA is the strongest predictor of healthy aging and lower probability of disability in older men [8]. Further, PA in older age was reported to positively affect leukocyte telomere length [9], the most important marker of biological aging [10]. Active older adults were also found to enjoy up to 3.2 years longer life without cardiovascular disease [11]. Moreover, researchers observed that PA in older age is associated with enhanced brain plasticity $[12,13]$ especially in the hippocampus [14]. The increased hippocampal
() Biomed Central

(c) 2014 Müller and Khoo; licensee BioMed Central Ltd. This is an Open Access article distributed under the terms of the Creative Commons Attribution License (http://creativecommons.org/licenses/by/2.0), which permits unrestricted use, distribution, and reproduction in any medium, provided the original work is properly credited. 
volume was reported to significantly influence memory functions with improved cognitive performance in older adults [14]. Finally, PA was found to have a direct impact on mental health in older adults because being physically active is associated with reduced risk of dementia, depression [15] and anxiety [16].

Based on this evidence the WHO recommends older adults to be moderately physically active for a minimum duration of 150 minutes throughout the week, or to at least increase PA levels according to individual abilities in order to enjoy general health benefits [2].

Despite the global release of PA recommendations, studies on older adults indicate low participation and a trend of decreasing PA with increasing age [17]. To address the lack of PA, various interventions aimed to increase PA levels in the older adult population have been developed and evaluated. According to the findings of eight reviews, several intervention components seem to be essential for successfully increasing PA participation in older adults: a) home-based or informal interventions, b) individual tailoring and self-monitoring, c) application of theoretical frameworks, d) not in combination with other interventions, e) moderate intensity and low weekly PA frequency, f) simple and convenient lifetime activities, as well as g) low cost [18-25].

Non-face-to-face interventions are conducted with reduced or no in-person interaction between the intervention provider and participants. They present a novel way to promote PA in older adults. These interventions come with considerable administrative as well as logistic benefits in terms of cost-effectiveness, ease of dissemination and outreach. They can also incorporate the components of successful PA interventions listed above [10,26-28]. The increasing use and social integration of modern media among older adults underpins the PA promotion opportunities of non-face-to-face interventions [29]. Older adults are the fastest growing segment of internet users with $53 \%$ of older Americans ( $\geq 65$ years) using the World-Wide-Web or email [30]. Irvine et al. [28] found that $70 \%$ of their older adult sample was online on a daily basis. Hence, this age group is increasingly keen to use modern computer technology [31] irrespective of gender [32]. Consequently, these advanced technologies have potential for new PA promotion strategies in addition to traditional and commonly applied telephone and print based programs [28]. However, no systematic review has evaluated PA interventions targeting older adults that were delivered almost entirely without direct face-to-face contact between study participants and the researcher.

Therefore, the aim of this review was to examine the published literature on non-face-to-face interventions designed to promote PA in community dwelling older adults.

\section{Methods}

\section{Literature search strategy}

A systematic search for non-face-to-face PA intervention studies targeting older adults published between $1^{\text {st }}$ January 2000 and $31^{\text {st }}$ May 2013 in the English language was performed using the literature databases Pubmed, Embase, CINAHL, SportDiscus, ScienceDirect and the Cochrane Library. For each database, the search was constructed using relevant medical subject headings (MeSH). The search terms 'physical activity', 'exercise' and 'walking' were combined with the terms for the intervention delivery mode: 'media', 'newspaper', 'TV', 'television', 'radio', 'internet', 'web', 'world-wide-web', 'e-mail', 'online', 'web-based', 'website', 'PC', 'mail', 'print', 'broadcast', 'video', 'phone' 'telephone' and with the terms for the target population; 'older adults', 'seniors', 'elderly', 'retiree'.

The search term "walking" was specifically included because it is a popular form of PA with a high public health impact especially among older adults $[33,34]$.

Reference lists of relevant publications were scanned for eligible articles. Experts in the field of PA research were contacted to obtain additional papers.

\section{Study selection}

The following inclusion criteria were defined before the systematic literature search was performed: a) Study sample consisted of healthy, community dwelling adults aged 50 years or older (because there is no globally accepted definition of older adulthood 50 years was chosen to include relevant studies that have lower cut-offs in terms of age), b) Study implemented a non-face to-face intervention to initiate, increase and/or maintain PA, exercise and/or walking, c) Quantitative data was used to report the effectiveness of interventions. The authors opted against including only randomized controlled trials (RCTs) in order to provide a more comprehensive picture. Unpublished work, review papers, meta-analysis studies and articles that focused on either patients or senior athletes were excluded. When uncertainty about article inclusion occurred the authors came to agreement through discussion. Figure 1 displays the flow diagram of the search for relevant articles.

\section{Risk of bias assessment}

The authors evaluated the risk of bias of included papers independently using the Cochrane risk of bias assessment tool [35]. This instrument assessed the following features: sequence generation, allocation sequence concealment, blinding, incomplete outcome data, selective outcome reporting and other potential sources of bias. Low risk of bias is indicated by answering 'Yes' to the respective questions, whereas 'No' signifies a high risk of bias. The option 'Unclear' indicates a lack of sufficient 


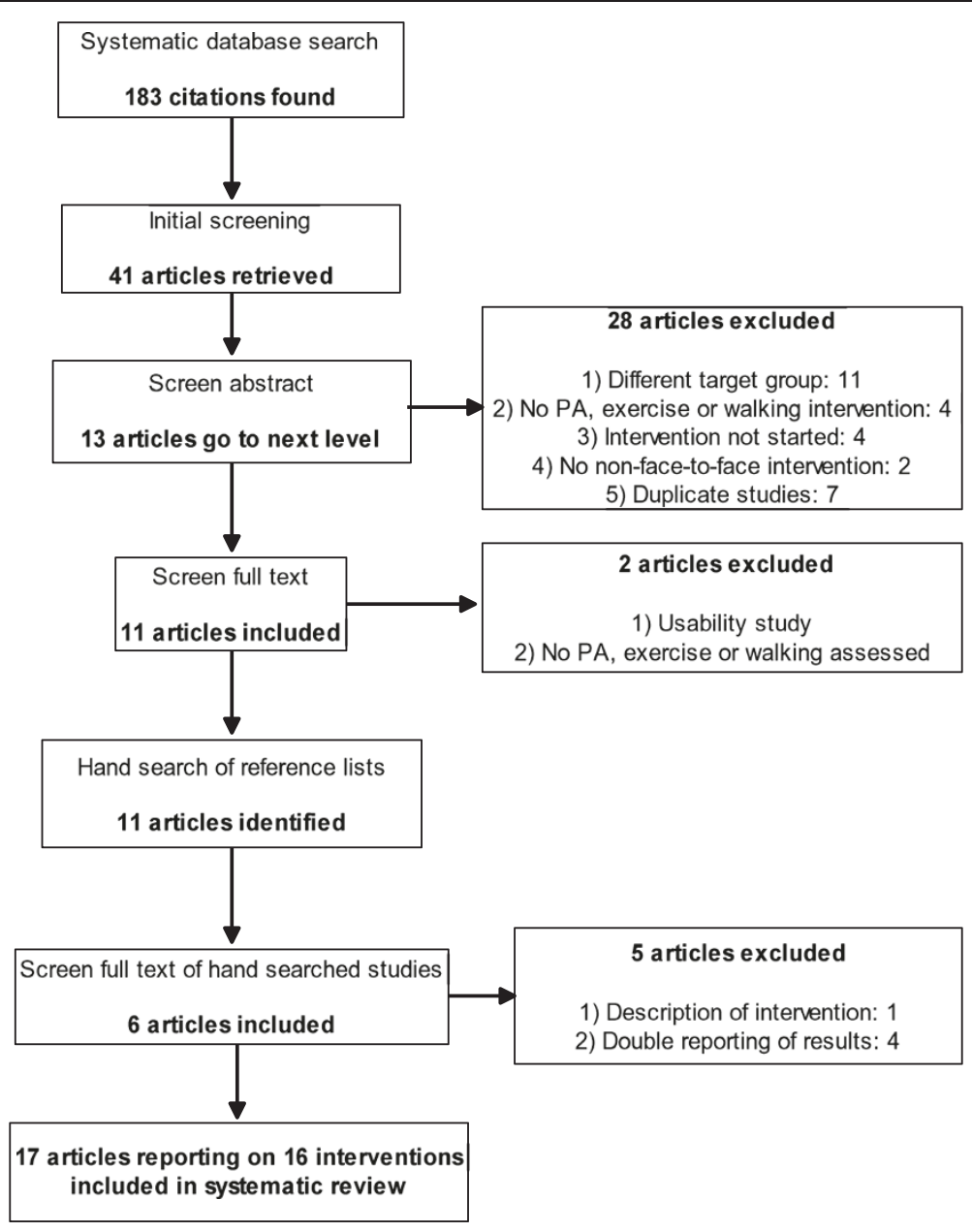

Figure 1 Flow diagram of the search for relevant articles.

information for risk assessment or uncertainty about the risk of bias. Although the instrument was specifically developed for RCTs, the Cochrane collaboration suggested that it can also be applied for other research designs [35]. Any discrepancies between the authors regarding the risk of bias were discussed and consensus was reached.

\section{Data extraction}

The following data were extracted from each article for coding using a standardized form: author and country, study focus, participants, study design, theoretical background of the intervention and intervention components, intervention description, outcome measures and outcomes. Data extraction was performed by the corresponding author and checked for accuracy by the co-author.

\section{Results}

The authors identified 183 unique citations through data-base search. After an initial screening 142 records were rejected. Of the 41 remaining articles, 28 were excluded because the described studies did not meet the inclusion criteria. The full text of 2 of the 13 remaining articles was read because the abstract did not provide the necessary inclusion information. These 2 articles were excluded because 1 assessed the usability of a PA intervention and the other did not report data on PA, exercise or walking. After hand searching and forward citation tracking the remaining articles, another 11 papers were added. Of these, 5 were excluded because 1 only described an intervention and 4 presented results that were already reported in the included articles. Results of the study by van Stralen $[36,37]$ were reported in two separate papers, and therefore both papers were included in the analysis. Finally, 17 articles describing 16 intervention-studies were included in the review. The majority of studies were RCTs $(n=11)$, whereas the remaining studies employed different designs $(n=5)$ (see Additional file 1 for the risk of bias assessment).

\section{Study characteristics}

All included studies were conducted in developed countries (USA: $n=11$, Australia: $n=3$, New Zealand: $n=1$, 
Holland: $\mathrm{n}=1$ ). The sample size of the studies varied from 31 to 2503, with 13 studies reporting more than $60 \%$ female participants. Information on education of the intervention participants was provided in 15 studies. The percentage of participants with at least a college degree (higher education) ranged from $27 \%$ to $72.3 \%$. Nine studies employed only one non-face-to-face intervention delivery strategy to promote PA with most studies using print or telephone-based approaches $(n=11)$. However, internet interventions are emerging $(n=3)$. Every intervention was theory-guided, with the Social Cognitive Theory (SCT, $\mathrm{n}=10$ ) and the Transtheoretical Model of Behavioral Change (TTM, $n=6$ ) the most applied. Other frequently reported intervention components were tailoring $(n=15)$, goal setting $(n=8)$, self-monitoring $(n=6)$ and motivation $(n=6)$. Self-report instruments to measure PA were used in all 16 studies with the Community Healthy Activities Model Program for Seniors (CHAMPS) being the most frequently applied $(n=5)$. Additionally, one study used behavioral observations at popular walking sites in order to assess changes in walking frequency in the respective intervention communities [38]. Accelerometer counts complemented self-report data in one study [26]. Thirteen studies reported main PA outcomes in weekly time spent in PA or walking and/or weekly energy expenditure. Eight interventions were short-term and lasted between one week and three months. Long-term interventions $(n=8)$ lasted up to 24 months. Nine studies conducted post-intervention follow-up analysis, which ranged between 1 and 18 months. Table 1 summarizes important information from each of the interventions.

\section{Effectiveness of interventions}

Of the 16 studies, 14 reported significant improvements in PA over the respective study periods (1 week to 24 months). No changes in PA measured with the Yale Physical Activity Survey (YPAS) was observed by Greaney et al. [41] where PA scores between baseline, postintervention and 12 months follow-up did not vary. Only the internet-based study by Hageman et al. [10] reported a non-significant decrease of PA in terms of daily calorie expenditure and time spent in moderate or greater PA over the previous week.

PA levels were maintained after the intervention stimulus was removed in all but one study [41] that collected follow-up data. Ammann and colleagues [47] conducted a short, one week internet intervention (website), and reported that the positive effects sustained after one month follow-up. Strong PA maintenance was also reported by Castro et al. [40]. The researchers found that $73 \%$ of a mail and $57 \%$ of a mail plus phone intervention maintained PA levels over the 12 months postintervention follow-up period. Martinson et al. [27] conducted follow-up analysis after a 6-month telephone intervention and found that PA maintenance of the intervention group increased from 43.4\% (6 months follow-up) to $50.1 \%$ after 18 months without the intervention stimulus.

\section{Intervention dose}

Intervention dose (completed phone calls, website visits, use of written material) was assessed in six studies. The study by van Stralen et al. reported that $98 \%$ of the print intervention participants read all three letters that were sent during the 4-month intervention period [37]. King et al. [26] conducted a 12-month phone intervention and recorded a mean of 12.5 completed calls per participant. Web-based studies $(n=3)$ showed differing doses. Hageman et al. [10] found that $83 \%$ of the study participants read all three online newsletters, whereas Ammann and colleagues [47] stated that only 4\% of their sample visited the intervention website at least twice within one week. The study by Irvine et al. [28] reported a mean of 15.2 PA website visits ( \pm 9.2 visits) during the 12-week intervention. As a result of an extensive 8 weeks paid media PA intervention (TV, radio, newspaper, website, events) $90 \%$ of the study community was aware of the campaign [38].

\section{Discussion}

The aim of this systematic review was to determine how far non-face-to-face PA interventions in older adults can lead to PA adoption, increase and/or maintenance. The results suggest that the respective interventions are effective in enhancing PA participation in healthy, community dwelling older adults.

Only two studies presented contradictory results. Greaney et al. [41] reported no change in PA levels after a 12-month print and phone intervention. However, the study sample was already reasonably active and further increase in PA was less likely [49]. Further, no measure of the intervention dose, literacy or cognitive status of the participants was undertaken. Hence, it is unclear whether the study participants read and understood the printed material [13]. The study by Hageman et al. [10] reported non-significant decreases in PA time and energy expenditure after a web-based newsletter intervention. This seems surprising because the perception of barriers decreased and PA self-efficacy increased. Though, a considerable number of research studies have shown that changes in motivational constructs do not necessarily lead to actual behavior [50,51]. A study by Sheeran [52] found inclined abstainers (non-actors with behavioral intentions) to be most responsible for not showing the respective behavior. Finally, this was the first internet-based PA intervention targeting older adults. Hence, it can be inferred that older adults were not as technologically literate compared to today [29] 


\begin{tabular}{|c|c|c|c|c|c|}
\hline Reference & Study design & Demographics & Intervention components & PA measures & Results \\
\hline Ball et al. [39] & RCT & $\begin{array}{l}66 \text { physically underactive } \\
\text { adults ( } 45-78 \text { years, } 73 \% \\
\text { female), Australia }\end{array}$ & $\begin{array}{l}12 \text { weeks print, and print plus phone } \\
\text { individual PA counselling; SCT, TTM; } \\
\text { self-monitoring, goal setting, } \\
\text { incentives, tailored feedback for } \\
\text { print plus phone group }\end{array}$ & $\begin{array}{l}\text { CHAMPS: global PA scores, } \\
\text { MET-min/wk for PA and } \\
\text { walking measured at baseline, } \\
12 \text { and } 16 \text { weeks }\end{array}$ & $\begin{array}{l}\text { Significant increase of global PA } \\
\text { scores from baseline to } 12 \text { weeks } \\
\text { maintained after } 16 \text { weeks, } \\
\text { - significant increase in } \\
\text { MET-min/wk maintained after } \\
16 \text { weeks, } \cdot \text { significant increase } \\
\text { in MET-min/wk for walking from } \\
\text { baseline to } 12 \text { weeks and from } \\
12 \text { weeks to } 16 \text { weeks in print } \\
\text { plus phone group }\end{array}$ \\
\hline Castro et al. [40] & RCT & $\begin{array}{l}140 \text { sedentary adults } \\
(50-65 \text { years, } 43 \% \text { female, } \\
15.6 \text { years } \pm 2.7 \text { years } \\
\text { education), USA }\end{array}$ & $\begin{array}{l}12 \text { months mail only, and mail plus } \\
\text { phone PA maintenance intervention } \\
\text { after } 12 \text { months PA adoption intervention; } \\
\text { SCT; motivation, self-monitoring, relapse } \\
\text { prevention and overcoming barriers, } \\
\text { tailored feedback }\end{array}$ & $\begin{array}{l}\text { Self-report exercise adherence } \\
\text { and activity log: monthly } \\
\text { exercise adherence based on } \\
\text { prescribed exercise sessions } \\
\text { recorded for } 12 \text { months }\end{array}$ & $\begin{array}{l}\text { During maintenance period PA } \\
\text { levels remained over baseline, } \\
\text { - mail only intervention with } \\
\text { significantly higher PA maintenance }\end{array}$ \\
\hline Greaney et al. [41] & RCT & $\begin{array}{l}966 \text { adults ( } \geq 60 \text { years, } \\
71.4 \% \text { female, } 12.9 \pm \\
2.9 \text { years education), USA }\end{array}$ & $\begin{array}{l}\text { Written material, newsletters, Expert } \\
\text { System Assessment and coaching } \\
\text { calls for } 12 \text { months; TTM; stage } \\
\text { specific tailored feedback, } \\
\text { encouragement }\end{array}$ & $\begin{array}{l}\text { YPAS: exercise, household and } \\
\text { recreational PA during typical } \\
\text { week in previous month, YPAS } \\
\text { score (higher score: more active), } \\
\text { measured at baseline, } 12 \text { and } \\
24 \text { months }\end{array}$ & $\begin{array}{l}\text { No significant change in YPAS } \\
\text { scores (baseline: } 46 ; 12 \text { months: } \\
46 ; 24 \text { months: } 47) ;\end{array}$ \\
\hline Hooker et al. [42] & $\begin{array}{l}\text { Community } \\
\text { intervention at } \\
13 \text { sites (not } \\
\text { randomized) }\end{array}$ & $\begin{array}{l}447 \text { sedentary or irregular } \\
\text { active adults ( } \geq 50 \text { years, } \\
78.3 \% \text { female, } 27.2 \% \text { higher } \\
\text { education), USA }\end{array}$ & $\begin{array}{l}18 \text { phone calls in } 12 \text { months after } \\
\text { initial face-to-face meeting where } \\
\text { individual PA plan was developed; } \\
\text { SCT; tailored support and feedback }\end{array}$ & $\begin{array}{l}\text { CHAMPS: total PA energy } \\
\text { expenditure, total hours PA } \\
\text { and PA frequency per week } \\
\text { measured at baseline, } 6 \text { and } \\
12 \text { months }\end{array}$ & $\begin{array}{l}\text { Significant median increase in PA } \\
\text { energy expenditure (baseline- } 6 \\
\text { months: } 644 \mathrm{kcal} / \mathrm{wk} \text {; baseline-12 } \\
\text { months: } 707 \mathrm{kcal} / \mathrm{wk} \text { ), } \cdot \text { significant } \\
\text { median increase in total PA hours } \\
\text { (baseline- } 6 \text { months: } 2.75 \mathrm{~h} / \mathrm{wk} \text {; } \\
\text { baseline- } 12 \text { months: } 3 \mathrm{~h} / \mathrm{wk} \text { ), } \\
\text { - significant increase in PA } \\
\text { frequency (baseline- } 6 \text { months: } \\
3 \text { times/wk; baseline- } 12 \text { months: } \\
4 \text { times/wk), } \cdot \text { no changes between } \\
6 \text { and } 12 \text { months }\end{array}$ \\
\hline King et al. [26] & RCT & $\begin{array}{l}189 \text { underactive adults } \\
(\geq 55 \text { years, } 69.3 \% \text { female, } \\
16.2 \pm 1.9 \text { years education), } \\
\text { USA }\end{array}$ & $\begin{array}{l}12 \text { months PA phone counselling by } \\
\text { human counsellor, or by computer } \\
\text { controlled interactive system } \\
\text { supplemented by info mailings and } \\
\text { pedometer; SCT, TTM; tailoring, } \\
\text { self-monitoring }\end{array}$ & $\begin{array}{l}\text { Stanford 7-Days Physical } \\
\text { Activity Recall: energy } \\
\text { expenditure and weekly } \\
\text { minutes in moderate- } \\
\text { vigorous PA; CHAMPS } \\
\text { measured at baseline, } \\
6 \text { and } 12 \text { months; } \\
\text { Accelerometer for } 7 \mathrm{~d} \\
\text { ( } 26 \% \text { of sample) } \\
\text { recording moderate PA }\end{array}$ & $\begin{array}{l}\text { Significantly greater mean energy } \\
\text { expenditure and mean PA minutes } \\
\text { per week in intervention groups } \\
\text { compared to controls }(6 / 12 \\
\text { months), } \cdot \text { significantly more days } \\
\text { of } 30 \text { minutes moderate-vigorous } \\
\text { PA per week in intervention groups } \\
(6 / 12 \text { months), } \cdot \text { significantly more } \\
\text { participants met WHO PA } \\
\text { recommendation in intervention } \\
\text { groups }(6 / 12 \text { months), } \cdot \text { significantly } \\
\text { more PA based on accelerometer } \\
\text { counts in intervention groups }\end{array}$ \\
\hline
\end{tabular}


Table 1 Summary of non-face-to-face PA intervention studies targeting older adults (Continued)

186 low active adults

( $\geq 65$ years, $66.2 \%$ female

New Zealand

Lee et al. [44]

270 inactive adults

$65-74$ years, $65.3 \%$

female, 32.3\% higher

education), Australia

Martinson et al. [27] RCT

van Stralen et a.

RCT

$[36,37]$

971 adults ( $\geq 50$ years

$57 \%$ female, $52 \%$ middle

or higher education),

Holland

1049 moderately active higher education), USA
$44.1 \%$ higher education)

Eight PA counselling calls in 3 months; TTM: individual goal setting, providing knowledge and motivation, problem solving and relapse prevention tailoring

Interactive booklet and individual PA counselling calls for 12 weeks (five phone calls); participatory action research; tailoring, goal setting, self-monitoring, motivation adults (50-70 years,

phone sessions in 6 months, followed by monthly and bimonthly calls in year one and two; control group with information material and 4 newsletters; SCT; relapse prevention, self-management (goal setting, problem solving, identification of barriers, self-monitoring, environmental (ues), tailoring

Three computer tailored PA advice letters; or additional environmenta focused information on PA opportunities in neighborhood plus access to e-buddy system for 4 months; SCT, I-Change Model, TTM, health action process approach, precaution adoption process model, self-regulation theory, selfdetermination theory; tailoring
Auckland Heart Study Physical Significantly more total leisure time Activity Questionnaire: PA (leisure, walking, occupationa domestic) and number of domestic) and number of $\begin{array}{ll}\text { minutes per time measured } & \text { time in intervention group from } \\ \text { at baseline, 3, } 6 \text { and } 12 \text { months } & \text { baseline to } 12 \text { months ( } 86.6 \mathrm{~min} / \mathrm{wk}) \text {, }\end{array}$ (48.9 min/wk SE $21.6 \mathrm{~min} / \mathrm{wk})$ ( $48.9 \mathrm{~min} / \mathrm{wk}$, SE $21.6 \mathrm{~min} / \mathrm{wk}$, significantly more total leisure time in intervention group from - significantly more participants in intervention group met PA recommendations after 12 months compared to control group

IPAQ short form: frequency days, times) and duration (minutes) of walking and PA per week measured at baseline and 12 weeks

Significant differences between intervention and control group in recreational walking and PA at post intervention, $\cdot$ significant gain in recreational walking and PA (27 minutes/wk) in intervention group

CHAMPS: total kcal/wk, weekly kcal spent in moderate to vigorous PA; meeting PA intervention group reported more
kcal/wk expended at $6(p<0.03)$ $\mathrm{kcal} / \mathrm{wk}$ expended at $6(p<0.03)$ - intervention group continued to increase $\mathrm{kcal} / \mathrm{wk}$ expenditure over 24 months, $\cdot$ intervention group participants reported significantly more $\mathrm{kcal} / \mathrm{wk}$ expenditure in $\mathrm{PA}$ than controls at $6(p<0.03), 12$ $(p<0.04)$ and 24 months $(p<0.01)$ - significantly more intervention group participants maintained PA at $6(p<0.001), 12(p<0.03)$, and 24 months $(p<0.001)$

Dutch Short Questionnaire to assess Health enhancing PA: total weekly PA and total weekly PA minutes, compliance to PA guidelines, self-rated PA level measured at baseline

3, 6 and 12 months follow-up

Significant increase in total PA at 3 months with further increase at 6 months in intervention groups compared to controls, $\cdot$ intervention groups complied with PA guidelines 1.6 times (3 months) and 2.5 times

(6 months) more than controls,

- insufficiently active

intervention participants more likely to have initiated

PA at 3 months than controls with further increase at 6 months, 


$\begin{array}{lll}\text { Walker et al. [45] } & \begin{array}{l}\text { Randomized } \\ \text { by site community- } \\ \text { based controlled } \\ \text { clinical trial }\end{array} & \begin{array}{l}225 \text { rural, irregular active } \\ \text { older adults (50-69 years, } \\ 100 \% \text { female, 35\% higher } \\ \text { education), USA }\end{array}\end{array}$

Wilcox et al. [46]

Community study of 2503 underactive adults previously tested $\quad(\geq 50$ years, $80 \%$ female intervention (quasi $33 \%$ higher education) experiment)

Hageman et al. [10] RCT 31 inactive adults (50-69

Irvine et al. [28] RCT recruited from different sites over four years, USA years, $100 \%$ female, $51.7 \%$ higher education), USA

18 tailored PA newsletters and instructional video versus generic PA newsletters for 12 months; SC tailoring, motivation, overcoming barriers, goal setting

Six months phone PA counselling SCT, tailoring, goal setting, self-monitoring, motivation

\section{Internet interventions}

Three tailored versus non-tailored online newsletters in 3 months: $\mathrm{SCT}$; tailored information based on baseline assessment for one group

405 sedentary adults ( $\geq 55 \quad 12$ weeks multiple visit stand-alone years, $69 \%$ female, $82 \%$ some college education), USA videos; Theory of Planned Behavior (TPB); goal setting, tailoring

235 adults (60-89 years, 57\% female, $72.3 \%$ higher education), Australia
Website for individual PA advice,

1 week online; TPB, TTM

tailored feedback
Modified 7-Day Activity Recall: daily PA minutes, daily PA kcal expended, weekly time engaged in strength/flexibility training measured at baseline, 6 and 12 months

CHAMPS: min/wk spent in moderate to vigorous PA total PA, meeting PA guidelines measured at baseline and 6 months

Modified 7-day Activity recall: daily energy expenditure weekly PA minutes measured at baseline and 3 months

Self-developed tool measuring weekly PA frequency and PA minutes applied at baseline, 12 and 24 weeks

Active Australia Survey: PA levels (duration, frequency of walking, PA in previous week), total PA minutes, PA sessions measured at baseline, 1 week and 1 month
- significant increase in total days/wk of sufficient PA in from baseline $(4.2 \pm 2.2)$ to 12 moups $(4.7 \pm 2.0)$ with medium effect sizes,

$(4.7 \pm 2.0)$ with medium effect sizes,
- only intervention with PA opportunities information significantly effective (small effect) in increasing total PA min/wk

Intervention and control group significantly increased on all PA measures from baseline to 6 months, $\cdot$ both groups significantly increased weekly stretching and strength exercise from baseline to 12 months, - only tailored group significantly increased daily moderate or higher intensity PA minutes $(337.65 \pm 675.4 \mathrm{~min} / \mathrm{wk}-509.88 \pm$ $749.5 \mathrm{~min} / \mathrm{wk}, \mathrm{p}<.001)$

Significant PA increase and significant increase of participants meeting PA guidelines $(p<.001)$

Non-significant decrease in energy expenditure (mean decrease of calories expended daily 6.4\%) and weekly PA minutes (mean decrease 6.4\%) for both groups

Large PA gains from baseline to 12 weeks (eta square $=0.17$ ), - Medium to large effect sizes for cardiovascular, stretching, strengthening, balance activities and weekly PA minutes from baseline to 12 weeks maintained after 24 weeks

Significant increase in total weekly PA minutes and PA sessions from baseline to 1 month (327 $\mathrm{min} \pm 335$ min to $404 \mathrm{~min} \pm 345 \mathrm{~min}$; 8.3 sessions \pm 7.2 sessions to 10.1 session \pm 7.6 sessions), - non-significant increase in walking minutes, moderate and vigorous intensity PA 
Table 1 Summary of non-face-to-face PA intervention studies targeting older adults (Continued)

\begin{tabular}{|c|c|c|c|c|c|}
\hline \multicolumn{6}{|c|}{ Other media interventions } \\
\hline King et al. [48] & RCT & $\begin{array}{l}37 \text { inactive adults ( } \geq 55 \text { years, } \\
43.4 \% \text { female, } 16.8 \pm 2.2 \text { years } \\
\text { education), USA }\end{array}$ & $\begin{array}{l}\text { Educational material, and daily PA } \\
\text { feedback delivered via PDA for } 8 \\
\text { weeks; or written material only; } \\
\text { SCT; tailored PA goal setting } \\
\text { and feedback }\end{array}$ & $\begin{array}{l}\text { CHAMPS: minutes/wk spent in } \\
\text { moderate to vigorous PA, total } \\
\text { PA, meeting PA guidelines } \\
\text { measured at baseline and } \\
8 \text { weeks }\end{array}$ & $\begin{array}{l}\text { Significantly higher 8-week } \\
\text { moderate PA minutes in PDA } \\
\text { group compared to controls } \\
\text { (PDA mean = 310.6, SD 267.4 } \\
\text { minutes; control mean }=125.5 \text {, } \\
\text { SD } 267.8 \text { minutes; } P=0.048 \text { ) } \\
\text { and caloric expenditure in } \\
\mathrm{kcal} / \mathrm{kg} / \mathrm{wk} \text { in moderate PA } \\
(\mathrm{PDA} \text { mean }=19.1, \mathrm{SD} 16.8 \\
\mathrm{kcal} / \mathrm{kg} / \mathrm{wk} \text { control mean }=7.8 \text {, } \\
\mathrm{SD} 16.8 \mathrm{kcal} / \mathrm{kg} / \mathrm{wk} ; \mathrm{p}=0.05 \text { ) }\end{array}$ \\
\hline Reger et al. [38] & $\begin{array}{l}2 \text { community } \\
\text { longitudinal study } \\
\text { (quasi experiment) }\end{array}$ & $\begin{array}{l}463 \text { adults ( } 50-65 \text { years, } \\
68 \% \text { female, } 24.7 \% \text { higher } \\
\text { education), USA }\end{array}$ & $\begin{array}{l}\text { Promoting walking in Wheeling, } \\
\text { USA using paid media (newspaper, } \\
\text { TV, radio) and public relations } \\
\text { events for } 8 \text { weeks; TPB, elaboration } \\
\text { likelihood model for advertisements }\end{array}$ & $\begin{array}{l}\text { Behavioral observation of } \\
\text { walking: counting walkers } \\
\text { at popular walking sites; } \\
\text { self-developed PA } \\
\text { questionnaire: weekly days } \\
\text { of brisk walking and moderate } \\
\text { to vigorous PA, hours and } \\
\text { minutes devoted to activity } \\
\text { per day measured at baseline } \\
\text { and } 8 \text { weeks }\end{array}$ & $\begin{array}{l}\text { Significant }(23 \%) \text { increase in } \\
\text { walking in intervention } \\
\text { community compared to } \\
6 \% \text { decrease in comparison } \\
\text { community }(p<0.0001 \text {, } \\
\mathrm{OR}=1.31,95 \% \mathrm{Cl}=1.14-1.50) \text {, } \\
\cdot 32.2 \% \text { met walking guidelines } \\
(150 \text { minutes/wk) in the } \\
\text { intervention community } \\
\text { compared to } 18 \% \text { in comparison } \\
\text { community }(\mathrm{p}<0.05, \mathrm{OR}=2.12 \text {, } \\
95 \% \mathrm{Cl}=1.41-2.24), \cdot \text { no } \\
\text { significant effects in other PA }\end{array}$ \\
\hline
\end{tabular}


and therefore did not benefit as much as participants recruited for more recent interventions $[28,47]$.

\section{Intervention components}

Although it is difficult to compare heterogeneous PA interventions that applied disparate methodologies it is possible to identify some interventional features that may influence PA participation in older adults. As stated in previous reviews $[22,23]$ and mirrored in this review a theoretical framework seems to be an essential interventional element for PA interventions in older adults. Yet, although all the interventions applied at least one theory, the effects on PA outcomes cannot be inferred. Moreover, Prestwich et al. [53] conducted a meta-analysis and reported that theory application in health behavior interventions, including PA, has only minimal effects on the respective behavioral outcomes. Small effect sizes were also found for theoretically framed internet interventions targeting PA [54]. These results were largely drawn on the basis of SCT and TTM, the same theories that were frequently applied in the studies included in the present review. Therefore, future intervention studies might benefit from applying theories that go beyond cognitive, social and emotional constructs (like in SCT and TTM).

All studies except one [38] applied individual tailoring strategies. Tailoring can be accomplished in various ways and was found to increase the likelihood of successful health interventions because it increases the perception of personal relevance for intervention participants [55]. According to a review by Lustria et al. [55] there are three tailoring strategies that can be applied in intervention studies: personalization, feedback and adaptation. The first two are common, but the last strategy requires more sophisticated procedures because tailoring content needs to be adapted to changing cognitions and behaviors during the intervention. The effects of tailoring versus non-tailoring in terms of PA participation was assessed in three of the reviewed studies. Walker et al. [45] and King et al. [48] incorporated all three tailoring strategies and reported that tailored interventions were more effective in increasing PA compared to non-tailored interventions. Hageman and colleagues [10] used only baseline information for tailoring and did not adapt the content during the 3-month online newsletter intervention. The decrease in PA after the intervention in both study groups (tailored and non-tailored) suggests that extensive tailoring leads to increased intervention effects. Though, more research is needed to gain further insights.

Intervention delivery was mainly by print and phone but internet-based interventions have recently received more research attention and were found to be an effective and economically viable way to influence PA behavior in older adults [28,47]. However, web-based interventions might systematically exclude populations with lower education and less income who have limited computer and internet access. This is critical because these populations are usually also less active compared to people in higher socio economic strata [56]. Ammann et al. [47] reported that $73 \%$ of the intervention participants in their study had higher education levels. Similarly, Irvine et al. [28] recorded that $82 \%$ of their sample had at least some college education. Researchers of both studies acknowledged that their samples were unlikely to be representative of the general older adult population and that the positive study results must be viewed with caution. In comparison, Hageman et al. [10] recruited a more balanced sample in terms of education (51.7\% with higher education) and reported pessimistic intervention results. Overall, these studies suggest that print and phone interventions might remain a valid intervention strategy to increase PA in older adults with low social economic status.

\section{Outcome measures}

A diverse range of self-report PA measures was applied across the studies of the current review. Self-report instruments come with general limitations in terms of misreporting and lack of sensitivity in detecting certain PA changes. According to a recent review, results from PA questionnaires for older adults showed only low to medium correlations with accelerometer counts (median: Spearman $r=0.4$, Pearson $r=0.345$ ) [57]. Despite these limitations, the use of self-report measures is widely accepted because of cost and logistic benefits compared to objective instruments [19]. Though, the use of objective measures like accelerometers is desirable in order to provide a more precise picture of the effects of non-faceto-face PA interventions in older adults.

Only six studies reported on the dose of the intervention stimulus. According to Ammann et al. [47] a mere $4 \%$ of the study sample visited the study website at least twice during the one week intervention period and participants spent just 16.3 minutes reviewing the content. However, PA increased significantly. In contrast, $83 \%$ of the participants in the study by Hageman et al. [10] read all the newsletters sent, but PA scores decreased insignificantly. Even though other studies indicated that higher stimulus dose leads to enhanced intervention effects $[28,58]$ more research is needed to reach clear understanding specific to non-face-to-face interventions.

\section{Limitations}

This review was limited to English language articles. Therefore, evidence from studies published in other languages might have been missed. Further, all included studies were conducted in developed countries (Australia, Holland, New Zealand and United States). Hence, the results of this review are not globally generalizable. Nonetheless, they can serve as a guide for region-specific 
studies that aim to explore the effectiveness of non-faceto-face PA interventions targeting older adults in various contexts and conditions.

Finally, it is worth noting that 14 of the 16 non-faceto-face PA studies reported positive intervention effects. It is likely that studies that had negative or null findings were either not published or were published as grey literature. This publication bias (publication associated with trial findings) is common in health research [59]. A systematic Cochrane review underpinned this notion and suggested that positive findings were more likely to be published than trials with negative or null findings (OR 3.90, 95\% CI 2.68 - 5.68) [59]. This systematic bias threatens the validity of reviews in general. Therefore, future review authors might consider looking for unpublished literature. Although these sources might lack scientific rigor, they can be useful in drawing a more realistic conclusion about intervention effects. Registering trials before the final results are known might eradicate this bias entirely.

Despite these limitations this review has the advantage of using a systematic rather than a narrative approach and constructed eligibility criteria that incorporated studies with various research designs and objective interventional outcomes. It is the first review to report on PA interventions targeting older adults that were conducted with reduced or no in-person interaction between intervention provider and study participants. Thus, the findings can serve as a baseline for future research.

\section{Conclusions}

It is widely accepted that PA is a viable method to enhance overall health and well-being in older adults and therefore reduces the economic burden caused by agingspecific health conditions. The implementation of nonface-to-face PA interventions that come with significant administrative and economic advantages appears to be an effective approach towards adoption, increase and maintenance of PA in older adults. This review reports positive short- and long-term outcomes of non-face-toface PA interventions and therefore underpins its relevance for community dwelling older adults. The authors recommend further research on older populations who are living in residential aged care facilities or other forms of supported accommodation. Here non-face-to face PA interventions might need to be complemented with inperson contact sessions to account for elevated individual care needs. Furthermore, researchers are encouraged to examine the effects of non-face-to-face PA interventions in multiple regions to enhance the generalizability of the study results. Finally, with the increasing competence of older adults in using new technologies, the use of smartphones for PA interventions should be explored in future research.

\section{Additional file}

Additional file 1: Risk of bias assessment (+: low risk of bias; -: high risk of bias; ?: unclear risk of bias; *: no RCT).

\section{Abbreviations}

UN: United nations; WHO: World health organization; PA: Physical activity; MeSH: Medical subject headings; RCT: Randomized controlled trial;

SCT: Social cognitive theory; TTM: Transtheoretical model of behavioral change; CHAMPS: Community healthy activities model program for seniors; MET: Metabolic equivalent; YPAS: Yale physical activity survey; SE: Standard error; IPAQ: International physical activity questionnaire; TPB: Theory of planned behavior; PDA: Personal digital assistant; OR: Odds ratio; Cl: Confidence interval.

\section{Competing interests}

The authors declare that they have no competing interests.

\section{Authors' contributions}

AMM developed the concept and design of the study, provided the systematic literature research, extracted the data and drafted the original manuscript. AMM \& SK contributed to the interpretation of the data and provided critical revisions to the manuscript. Both authors have read and approved the final manuscript.

\section{Acknowledgements}

This work was supported by the University of Malaya/Ministry of Higher Education (UM/MOHE) High Impact Research Grant (UM.C/625/1/HIR/MOHE/ ASH/02). The authors wish to thank Dr. Joan Fry for her academic advice and for proofreading the manuscript.

Received: 12 August 2013 Accepted: 5 March 2014

Published: 10 March 2014

\section{References}

1. United Nations, Department of Economic and Social Affairs: Population ageing and development 2012. New York: United Nations; 2012.

2. World Health Organization: Global recommendations on physical activity for health. Geneva: WHO; 2010

3. Marengoni A, Angleman S, Melis R, Mangialasche F, Karp A, Garmen A, Meinow B, Fratiglioni L: Aging with multimorbidity: a systematic review of the literature. Ageing Res Rev 2011, 10:430-439.

4. Reinhardt UE: Does the aging of the population really drive the demand for health care? Health Aff 2003, 22:27-39.

5. Paterson $\mathrm{DH}$, Jones $\mathrm{GR}$, Rice $\mathrm{CL}$ : Ageing and physical activity: evidence to develop exercise recommendations for older adults. Appl Physiol Nutr Metab 2007, 32(Suppl 2E):69-108.

6. Gremeaux V, Gayda M, Lepers R, Sosner P, Juneau M, Nigam A: Exercise and longevity. Maturitas 2012, 73:312-317.

7. Martinson BC, Crain AL, Pronk NP, O'Connor PJ, Maciosek MV: Changes in physical activity and short-term changes in health care charges: a prospective cohort study of older adults. Prev Med 2003, 37:319-326.

8. Södergren M: Lifestyle predictors of healthy ageing in men. Maturitas 2013, 75:113-117.

9. Ludlow AT, Zimmerman JBO, Witkowski S, Hearn JW, Hatfield BD, Roth SM: Relationship between physical activity level, telomere length, and telomerase activity. Med Sci Sports Exerc 2008, 40:1764-1771.

10. Hageman PA, Walker SN, Pullen CH: Tailored versus standard internetdelivered interventions to promote physical activity in older women. $J$ Geriatr Phys Ther 2005, 28:28-33.

11. Franco $\mathrm{OH}$, de Laet $\mathrm{C}$, Peeters A, Jonker J, Mackenbach J, Nusselder W: Effects of physical activity on life expectancy with cardiovascular disease. Arch Intern Med 2005, 165:2355-2360.

12. Colcombe SJ, Erickson KI, Scalf PE, Kim JS, Prakash R, McAuley E, Elavsky S, Marquez DX, Hu L, Kramer AF: Aerobic exercise training increases brain volume in aging humans. J Gerontol A Biol Sci Med Sci 2006, 61:1166-1170.

13. Erickson Kl, Gildengers AG, Butters MA: Physical activity and brain plasticity in late adulthood. Dialogues Clin Neurosci 2013, 15:99-108.

14. Erickson Kl, Voss MW, Prakash RS, Basak C, Szabo A, Chaddock L, Kim JS, Heo S, Alves H, White SM, Wojcicki TR, Mailey E, Vieira VJ, Martin SA, Pence BD, Woods 
$J A$, McAuley E, Kramer AF: Exercise training increases size of hippocampus and improves memory. Proc Natl Acad Sci 2011, 108:3017-3022.

15. Almeida OP, Norman P, Hankey G, Jamrozik K, Flicker L: Successful mental health aging: results from a longitudinal study of older Australian men. Am J Geriatr Psychiatry 2006, 14:27-35.

16. Pasco JA, Williams LJ, Jacka FN, Henry MJ, Coulson CE, Brennan SL, Leslie E, Nicholson GC, Kotowicz MA, Berk M: Habitual physical activity and the risk for depressive and anxiety disorders among older men and women. Int Psychogeriatr 2011, 23:292-298.

17. Motl RW, McAuley E: Physical activity, disability, and quality of life in older adults. Phys Med Rehabil Clin North Am 2010, 2:299-308.

18. King AC, Rejeski WJ, Buchner DM: Physical activity interventions targeting older adults. Am J Prev Med 1998, 15:316-333.

19. King AC: Interventions to promote physical activity by older adults. J Gerontol A Biol Sci Med Sci 2001, 56A(Suppl 2):36-46.

20. Conn VS, Valentine JC, Cooper HM: Interventions to increase physical activity among aging adults: a meta-analysis. Ann Behav Med 2002, 2:190-200.

21. van der Bij AK, Laurant MGH, Wensing M: Effectiveness of physical activity interventions for older adults: a review. Am J Prev Med 2002, 22:120-133.

22. Conn VS, Minor MA, Burks KJ, Rantz MJ, Pomeroy SH: Integrative review of physical activity intervention research with aging adults. J Am Geriatr Soc 2003, 51:1159-1168.

23. Cyarto EV, Moorhead GE, Brown WJ: Updating the evidence relating to physical activity intervention studies in older people. J Sci Med Sport 2004, 7(Suppl 1):30-38.

24. Taylor AH, Cable NT, Faulkner G, Hillsdon M, Narici M, van der Bij AK Physical activity and older adults: a review of health benefits and the effectiveness of interventions. J Sports Sci 2004, 22:703-725.

25. Ashworth NL, Chad KE, Harrison EL, Reeder BA, Marshall SC: Home versus center based physical activity programs in older adults. Cochrane Database Syst Rev 2005, 1:CD004017. doi:10.1002/14651858.CD004017.pub2.

26. King AC, Friedman R, Marcus B, Castro C, Napolitano M, Ahn D, Baker L: Ongoing physical activity advice by humans versus computers: the community health advice by telephone (CHAT) trial. Health Psychol 2007, 26:718-727

27. Martinson BC, Sherwood NE, Crain AL, Hayes MG, King AC, Pronk NP, O'Connor PJ: Maintaining physical activity among older adults: 24-month outcomes of the Keep Active Minnesota randomized controlled trial. Prev Med 2010, 51:37-44

28. Irvine $A B$, Gelatt VA, Seeley JR, Macfarlane P, Gau JM: Web-based intervention to promote physical activity by sedentary older adults: randomized controlled trial. J Med Internet Res 2013, 15:e19.

29. Wagner N, Hassanein K, Head M: Computer use by older adults: A multidisciplinary review. Comput Hum Behav 2010, 26:870-882.

30. Zickuhr K, Madden M: Older adults and internet use. http://pewinternet. org/Reports/2012/Older-adults-and-internet-use.aspx.

31. Juznic P, Blazic M, Mercun T, Plestenjak B, Majcenovic D: Who says that old dogs cannot learn new tricks? A survey of internet/web usage among seniors. New Library World 2006, 107:332-345.

32. Karavidas M, Lim NK, Katsikas SL: The effects of computers on older adult users. Comput Hum Behav 2005, 21:697-711.

33. Humpel N, Marshall AL, Iverson D, Leslie E, Owen N: Trial of print and telephone delivered interventions to influence walking. Prev Med 2004, 39:635-641.

34. Fortes C, Mastroeni S, Sperati A, Pacifici R, Zuccaro P, Francesco F, Agabiti N, Piras $G$, Amleto D, Ebrahim S: Walking four times weekly for at least $15 \mathrm{~min}$ is associated with longevity in a cohort of very elderly people. Maturitas 2013, 74:246-251.

35. Higgins JPT, Green S (Eds): Cochrane Handbook for Systematic Reviews of Interventions. Chichester (UK): John Wiley \& Sons; 2008.

36. van Stralen MM, de Vries H, Mudde AN, Bolman C, Lechner L: Efficacy of two tailored interventions promoting physical activity in older adults. Am J Prev Med 2009, 37:405-417.

37. van Stralen MM, de Vries H, Bolman C, Mudde AN, Lechner L: Exploring the efficacy and moderators of two computer-tailored physical activity interventions for older adults: a randomized controlled trial. Ann Behav Med 2010, 39:139-150.

38. Reger B, Cooper L, Booth-Butterfield S, Smith H, Bauman A, Wootan M, Middlestadt S, Marcus B, Greer F: Wheeling walks: a community campaign using paid media to encourage walking among sedentary older adults. Prev Med 2002, 35:285-292.

39. Ball K, Salmon J, Leslie E, Owen N, King AC: Piloting the feasibility and effectiveness of print- and telephone-mediated interventions for promoting the adoption of physical activity in Australian adults. J Sci Med Sport 2005, 8:134-142.

40. Castro CM, King AC, Brassington GS: Telephone versus mail interventions for maintenance of physical activity in older adults. Health Psychol 2001, 20:438-444.

41. Greaney ML, Riebe D, Garber CE, Rossi JS, Lees FD, Burbank PA, Nigg CR, Ferrone CL, Clark PG: Long-term effects of a stage-based intervention for changing exercise intentions and behavior in older adults. Gerontologist 2008, 48:358-367.

42. Hooker SP, Seavey W, Weidmer CE, Harvey DJ, Stewart AL, Gillis DE, Nicholl KL, King AC: The California active aging community grant program: translating science into practice to promote physical activity in older adults. Ann Behav Med 2005, 29:155-165.

43. Kolt GS, Schofield GM, Kerse N, Garrett N, Oliver M: Effect of telephone counseling on physical activity for low-active older people in primary care: a randomized, controlled trial. J Am Geriatr Soc 2007, 55:986-992.

44. Lee AH, Jancey J, Howat P, Burke L, Kerr DA, Shilton T: Effectiveness of a home-based postal and telephone physical activity and nutrition pilot program for seniors. J Obes 2011, 8:8.

45. Walker SN, Pullen CH, Boeckner L, Hageman PA, Hertzog M, Oberdorfer MK, Rutledge MJ: Clinical trial of tailored activity and eating newsletters with older rural women. Nurs Res 2009, 58:74-85.

46. Wilcox S, Dowda M, Griffin SF, Rheaume C, Ory MC, Leviton L, King AC, Dunn A, Buchner DM, Bazzarre T, Estabrooks PA, Campbell-Voytal K, Bartlett-Prescott J, Dowdy D, Castro CM, Carpenter RA, Dzewaltowski DA Mockenhaupt R: Results of the first year of active for life: translation of 2 evidence-based physical activity programs for older adults into community settings. Am J Public Health 2006, 96:1201-1209.

47. Ammann R, Vandelanotte $\mathrm{C}$, de Vries H, Mummery WK: Can a websitedelivered computer-tailored physical activity intervention be acceptable, usable, and effective for older people? Health Educ Behav 2013, 40:160-170.

48. King AC, Ahn DK, Oliveira BM, Atienza AA, Castro CM, Gardner CD: Promoting physical activity through hand-held computer technology. Am J Prev Med 2008, 34:138-142.

49. McAuley E, Morris KS, Motl RW, Hu L, Konopack JF, Elavsky S: Long-term follow-up of physical activity behavior in older adults. Health Psychol 2007, 26:375-380.

50. Milne $\mathrm{S}$, Orbell $\mathrm{S}$, Sheeran P: Combining motivational and volitional interventions to promote exercise participation: protection motivation theory and implementation intentions. Br J Health Psychol 2002 7:163-184

51. Gollwitzer PM, Sheeran P: Implementation intentions and goal achievement: a meta-analysis of effects and processes. Adv Exp Soc Psychol 2006, 38:69-119.

52. Sheeran P: Intention-behavior relations: a conceptual and empirical review. Eur Rev Soc Psychol 2002, 12:1-36.

53. Prestwich A, Sniehotta FF, Whittington C, Dombrowski SU, Rogers L, Michie $S$ : Does theory influence the effectiveness of health behavior interventions? Meta-analysis. Health Psychol 2013, doi:10.1037/a0032853.

54. Webb TL, Joseph J, Yardley L, Michie S: Using the internet to promote health behavior change: a systematic review and meta-analysis of the impact of theoretical basis, use of behavior change techniques, and mode of delivery on efficacy. J Med Internet Res 2010, 12:e4.

55. Lustria MLA, Cortese J, Noar SM, Glueckauf RL: Computer-tailored health interventions delivered over the web: review and analysis of key components. Patient Educ Couns 2009, 74:156-173.

56. Shankar A, McMunn A, Steptoe A: Health-related behaviors in older adults: relationships with socioeconomic status. Am J Prev Med 2010, 38:39-46.

57. Helmerhorst HJF, Brage S, Warren J, Besson H, Ekelund U: A systematic review of reliability and objective criterion-related validity of physical activity questionnaires. Int J Behav Nutr Phys Act 2012, 9:103.

58. Martinson BC, Crain AL, Sherwood NE, Hayes M, Pronk NP, O'Connor PJ: Maintaining physical activity among older adults: six months outcomes 
of the Keep Active Minnesota randomized controlled trial. Prev Med 2008, 46:111-119.

59. Hopewell S, Loudon K, Clarke MJ, Oxman AD, Dickersin K: Publication bias in clinical trials due to statistical significance or direction of trial results. Cochrane Database Syst Rev 2009, 1:MR000006. doi:10.1002/14651858.MR000006.pub3.

doi:10.1186/1479-5868-11-35

Cite this article as: Müller and Khoo: Non-face-to-face physical activity interventions in older adults: a systematic review. International Journal of Behavioral Nutrition and Physical Activity 2014 11:35.

\section{Submit your next manuscript to BioMed Central and take full advantage of:}

- Convenient online submission

- Thorough peer review

- No space constraints or color figure charges

- Immediate publication on acceptance

- Inclusion in PubMed, CAS, Scopus and Google Scholar

- Research which is freely available for redistribution 